\title{
Effects of temperature on the recruitment phenology and niche overlap of shallow epifaunal assemblages in southern New England
}

\author{
James F. Reinhardt ${ }^{1, *}$, Robert B. Whitlatch ${ }^{2}$, Richard W. Osman ${ }^{3}$ \\ ${ }^{1}$ Earth Resources Technology, NOAA Restoration Center, 1315 East-West Hwy, Silver Spring, Maryland 20910, USA \\ ${ }^{2}$ Department of Marine Sciences, University of Connecticut, 1080 Shennecossett Rd, Groton, Connecticut 06340, USA \\ ${ }^{3}$ Smithsonian Environmental Research Center, PO Box 28, 647 Contees Wharf Road, Edgewater, Maryland 21037, USA
}

\begin{abstract}
Recruitment phenology, or the timing of recruitment, can have a large influence on individuals and populations by affecting their exposure to adverse environmental conditions and interspecific competition. In this study, we examined whether temperature parameters could predict the timing of recruitment, the duration of recruitment and total recruitment in 18 benthic epifaunal species using partial least squares regression (PLSR) and ordinary least squares regression. Additionally, we used a null model to test whether temperature parameters and inter-annual variation in those parameters affect the temporal niche overlap of these benthic species. We specifically examined the recruitment patterns of non-native species to help illustrate how shifts in phenology may help drive changes in the community composition. Results from the PLSR helped determine the most instructive regressors for univariate least-squares models. For many (14 of 18) of the species examined, recruitment patterns could be predicted by seasonal growing degree days. Additionally, communities at cooler sites exhibited greater temporal niche overlap than assemblages found at warmer sites. Finally, we observed a unique pattern among invasive species, with more recent invaders recruiting later in the season, which may be a result of shifts in niche overlap. The findings of this study illustrate potential mechanisms for species coexistence and increased rates of invasion resulting from climate change.
\end{abstract}

KEY WORDS: Recruitment · Temperature · Long Island Sound · Niche overlap · Invasive species · Phenology $\cdot$ Fouling community

\section{INTRODUCTION}

The timing of life history events (i.e. phenology), including the timing of recruitment in marine organisms, can have a large influence on both individuals and populations. For example, species-specific seasonal differences in the timing of recruitment can be an important factor determining the nature and strength of competitive interactions, population growth rates, exposure to adverse environmental conditions and reproductive success (Yang \& Rudolf 2010). Ultimately, temporal variation in recruitment may help maintain biodiversity (Edwards \& Stachowicz 2012) or as we suggest, enhance invasion rates. In many cases, the timing of the recruitment of benthic marine invertebrates is controlled by abiotic factors such as temperature (Stachowicz et al. 2002), which controls gametogenesis and larval development (Westerman et al. 2009).

To reduce competition, organisms often partition resources. In seasonal environments resources can be temporally partitioned so that interspecific competition and the risk of competitive exclusion are reduced (Schoener 1974, Tokeshi 1986). Over time, 
processes occur that recycle limiting resources (Loreau 1989, 1992). Specifically, in shallow epifaunal communities substrate space becomes available through processes such as physical disturbance, predation, and senescence (Osman 1977, Sousa 1979, Mook 1981, Osman et al. 1992, Altman \& Whitlatch 2007). During the summer season in southeastern Connecticut, USA, open space is continuously generated; however, open space comprises only $\sim 15 \%$ of the total area on average (Altman \& Whitlatch 2007). Once space is cleared, new recruits can colonize the opening and compete for resources (Stachowicz \& Byrnes 2006, Altman \& Whitlatch 2007).

In seasonal environments, higher annual temperatures can reduce physical (temperature) constraints on niche partitioning and may expand the resource spectrum that can be partitioned among species (i.e. the time over which recruitment can take place is longer). Species may respond in a variety of ways to the expansion of the resource spectrum. For example, (1) species at the edge of their seasonal temperature limits may broaden the temporal distribution of recruitment to occupy the expanded resource, (2) species may broaden their recruitment curves, (3) species may shift their recruitment periods unidirectionally, (4) species may shorten their recruitment period as a result of faster maturation and larval development, (5) species may demonstrate idiosyncratic responses, meaning that there is no common response pattern among species, or (6) species recruitment periods may remain unchanged (Tokeshi 1986). However, species inhabiting locations near the extremes of their temperature thresholds (or limits of thermal tolerance) may respond differently. For instance, higher temperature may result in aestivisation in some tunicates (Tarjuelo et al. 2001) and ultimately limit the recruitment period, thus resulting in a shortened recruitment season. Regardless of the mechanism involved, shifts in species resource utilization may have effects on community dynamics. Studies have recorded changes in community structure within New England epifaunal assemblage over time (Dijkstra et al. 2011), but a complete understanding of the mechanisms responsible for these changes is still lacking. Understanding how temperature alters niche partitioning in space and time may improve our understanding of species coexistence and how temperature-related shifts and changes in resource utilization influence rates of species introductions or extinctions. In one hypothetical scenario, the shift of timing for recruitment to earlier in the year may open up resources later in the season and make species invasions at the end of the year more likely to occur. Null models are one way to examine niche overlap and changes that may be associated with temperature.

Null models randomize resource utilization curves to compare the niche overlap of a random species assemblage with the niche overlap empirically observed in the assemblage. Temporal niche partitioning has been examined using community niche overlap indices for a variety of organisms and systems, ranging from insect emergence (Tokeshi 1986) and flowering phenology (Gotelli \& Graves 1996) to ant foraging (Albrecht \& Gotelli 2001). In this study, our goal was to examine how shallow subtidal epifaunal species assemblages partition their seasonal recruitment, and understand how site-specific and interannual variation in temperature influences overlap.

To examine the effect of temperature on the overlap in species recruitment in shallow hard-substrate epifaunal communities, we compared water temperature parameters to community overlap using linear regression. Additionally, we examined the timing of the beginning of recruitment for each species and the length of the recruitment season in relation to a variety of temperature parameters to determine whether interannual temperature fluctuations can predict the timing of important phenological traits (i.e. the timing of recruitment). Two basic assumptions were made about the system: competition for space among recruits drive partitioning of resources, and community overlap reflects potential competition among recruits. We examined weekly recruitment data for 18 shallow-water epifaunal invertebrate species over $7 \mathrm{yr}$ and across 3 coastal sites in southern New England. This data set allowed us to look for patterns both within a single site as well as among sites. Finally, we compared the recruitment patterns of resident and non-native species to assess whether differences occur in the timing of recruitment between species within these groups. Understanding the relative timing and potential shifts of species (and the comparison of native and non-native species) within the epifaunal community may help us understand why coastal hard-substrates have become one of the most heavily invaded systems. As marine habitats continue to be affected by global change it is important to evaluate past patterns to help predict future impacts.

\section{MATERIALS AND METHODS}

\section{Data collection}

Recruitment and temperature data were collected at 3 coastal sites at eastern Long Island Sound, Con- 
necticut. Recruitment was monitored at Avery Point $\left(\mathrm{AP} ; 41^{\circ} 18^{\prime} 58.53^{\prime \prime} \mathrm{N}, 72^{\circ} 03^{\prime} 39.04^{\prime \prime} \mathrm{W}\right)$ Groton Long Point (GLP; $41^{\circ} 18^{\prime} 43.56^{\prime \prime} \mathrm{N}, 72^{\circ} 00^{\prime} 39.28^{\prime \prime} \mathrm{W}$ ), and Noank ( $\mathrm{NK}_{i} 41^{\circ} 19^{\prime} 24.66^{\prime \prime} \mathrm{N}, 71^{\circ} 59^{\prime} 09.25^{\prime \prime} \mathrm{W}$ ) (see http://invasions.si.edu/cgi/labs/ltreb for all data collected from 1991 to 2006). Temperature data have also been collected at all 3 sites since 2002. These sites are all within $7 \mathrm{~km}$ of each other. To estimate epifaunal recruitment, 4 replicate $100 \mathrm{~cm}^{2}$ PVC panels were repeatedly exposed at each site for $1 \mathrm{wk}$ periods. At AP and GLP, the panels were suspended face down $\sim 1 \mathrm{~m}$ below the water's surface from a floating dock. At NK, the panels were suspended from a fixed dock, so the panels' depth below the surface varied with the tidal state (typically $<1 \mathrm{~m}$ ). Each week, all individuals settling on the panels were counted and identified to the species level under a dissecting microscope, and new sets of blank panels were deployed. In the present study, we limited ourselves to 18 species (Table 1) that commonly occurred at most of the sites $(\sim 35 \%$ of the total number of species but $>90 \%$ of the individuals).

Table 1. List of species included in the analyses, with their growth form (solitary or colonial) and resident or non-native status (taken from Karlson \& Osman 2012 or J. T. Carlton pers. comm.)

\begin{tabular}{|lcc|}
\hline Species & $\begin{array}{c}\text { Colonial/ } \\
\text { solitary }\end{array}$ & $\begin{array}{c}\text { Non-native/ } \\
\text { resident }\end{array}$ \\
\hline Sponges & & \\
Halichondria bowerbanki & Colonial & Non-native \\
Hydroids & & \\
Obelia sp. & Colonial & Resident \\
Polychaetes & & \\
Spirorbis spp. & Solitary & Resident \\
Hydroides dianthus & Solitary & Resident \\
Bryozoans & & \\
Cryptosula pallasiana & Colonial & Resident \\
Schizoporella errata & Colonial & Resident \\
Electra pilosa & Colonial & Resident \\
Electra crustulenta & Colonial & Resident \\
Bugula turrita & Colonial & Resident \\
Bugula neritina & Colonial & Non-native \\
Bowerbankia gracilis & Colonial & Resident \\
Membranipora membranacea & Colonial & Non-native \\
Ascidians & & \\
Botryllus schlosseri & Colonial & Non-native \\
Botrylloides violaceus & Colonial & Non-native \\
Diplosoma listerianum & Colonial & Non-native \\
Didemnum vexillum & Colonial & Non-native \\
Molgula manhattensis & Solitary & Resident \\
Ascidiella aspersa & Solitary & Non-native \\
Ciona intestinalis & Solitary & Resident \\
Styela clava & Solitary & Non-native \\
\hline & & \\
\hline
\end{tabular}

HOBO® Tidbit temperature loggers were suspended with the PVC panels to collect hourly seawater temperature data at all sites. Data loggers were occasionally lost, resulting in some missing data points in the temperature records. Gaps in the data were filled by first creating a seasonal water temperature signal using all of the water temperature data from a particular site. Then, missing water temperatures were interpolated by performing a multiple linear regression including the seasonal signal and daily mean air temperature data from the Groton and Bridgeport airports $(<5 \mathrm{~km}$ and $71 \mathrm{~km}$ away from all sites) as independent variables ( $\mathrm{AP} \mathrm{r}^{2}=0.97$ GLP $^{2}=$ 0.91; NK $\mathrm{r}^{2}=0.96$ ). Temperature was then averaged over each year and over each month from January to October for all years. Growing degree days (GDDs) were also calculated for each year. GDDs were calculated as the average of the daily temperature minimum and maximum minus base temperature $\left(10^{\circ} \mathrm{C}\right)$. Negative values were excluded, and GDDs were cumulatively summed for each year. GDD are commonly used to predict phenological events and are good predictors because they represent a more meaningful sum of energy accumulation than temperature (e.g. Cross \& Zuber 1972).

\section{Niche overlap}

Temporal patterns in recruitment were investigated at the 3 sites over a 7 yr period (2002 to 2008). We excluded 2005 from the community niche analysis at AP and GLP because of missing data during the middle of the recruitment season; however, 2005 was still used to determine the date of recruitment onset and the length of the recruitment season. For the niche overlap analyses, the recruitment season was constrained from Day of Year 140-310 (May 19 to Oct. 27) at AP, 136-310 at GLP (May 15 to Oct. 27) and 152-312 (May 31 to Oct. 29) at NK. It was necessary to limit the seasonal recruitment domain to an ecologically relevant time period to avoid obvious seasonal constraints on recruitment and remove bias for clumped distributions. The domains employed in this study were defined based on GDD temperatures corresponding to more than $90 \%$ of the recruitment of all species. The starting day of the recruitment season was based on the average Day of Year when the water reached 20 GDD. This time point coincided with a rapid increase in recruitment activity (data not shown). The last day of the season was defined as the average last day of GDD accumulation. The last day of GDD accumulation is the last day of a calendar 
year when temperatures were greater than $10^{\circ} \mathrm{C}$. However, because recruitment was only measured weekly, the start and end dates are somewhat biased. Therefore, the recruitment domain actually covered from the first sampling day before the start date until the last sampling day before the end date. For each year and site, 21 to 23 weeks were included in the domain. The colonial bryozoan Cryptosula pallasiana recruited earlier than the beginning of the defined domain, albeit at very low levels $\left(<4\right.$ ind. $100 \mathrm{~cm}^{-2}$ $\mathrm{wk}^{-1}$ ). The species included in this study were encrusting and arborescent bryozoans, solitary and colonial ascidians and 2 polychaete species (Table 1 ). We performed the analyses with 18 species, 16 of which occurred at all sites at all times. In some years, Diplosoma listerianum was not always present at NK, and Didemnum vexillum did not always recruit at GLP.

Community niche overlap was estimated by first calculating the pairwise Czekanowski index (Legendre \& Legendre 1998) for all species during a single year at each site using the recruitment curves generated from the mean weekly replicate $(\mathrm{n}=4)$ samples.

$$
C z_{i j}=C z_{j i}=1-\frac{1}{n} \sum_{k=1}^{n}\left|P_{k i}-P_{k j}\right|
$$

The Czekanowski index $(\mathrm{Cz})$ is a symmetrical index that sums the difference between the proportion $(P)$ of recruits of species $i$ and the proportion of recruits of species $j$ at each resource state $(k)$ and normalizes this value to the number of resource states (n). Each week during the recruitment season (May through October) represented a separate resource state $\left(k_{i}=1 \ldots n\right)$. The values of the Czekanowski index range from 0 to 1 , where 0 represents no overlap, and 1 indicates complete overlap. All pairwise Czekanowski indices for a single year and site were averaged to estimate community niche overlap (Inger \& Colwell 1977). Although there are a variety of similarity indices that could have been used to determine overlap, our exploratory data analysis determined that results with different overlap metrics were qualitatively similar, and relatively insensitive to the similarity metric used. Thus, we used the Czekanowski index to be consistent with previous studies (e.g. Inger \& Colwell 1977).

To determine whether the observed community overlap was different than what should be expected at random, we created a null model. The null model of community niche overlap was built by first randomly shuffling the data matrix (recruitment curves of all species) for each year and site so that the peak and the shape of the recruitment patterns were retained but the starting points randomized (similar to the Mika randomization model in Tokeshi 1986). All pairwise Czekanowski overlaps were then calculated and averaged to obtain a randomized measure of community niche overlap. This procedure was repeated 10000 times to generate a distribution of random community niche overlaps for each site and year. The observed community niche overlap was considered significantly different from the null model if it was greater or less than $95 \%$ of the randomized community niche models. This null model preserved the shape and empirical auto-correlation of the recruitment curve through the randomization. Preserving the shape of the recruitment curve was most appropriate because we wanted to test the effect on shifts in the timing of recruitment (or shifts in the recruitment curve) rather than changes to the shape of the recruitment curve per se; retaining the shape of the recruitment curve results in a more conservative null model.

When comparing the community niche overlap to the seasonal temperature patterns, we used the difference between the empirical community niche overlap and the median of the randomized niche overlaps to standardize the observed overlap to a null model for each site and year (Abrams 1980).

\section{Phenology}

The time of first recruitment, or recruitment onset, was estimated by identifying the week in each year, no earlier than March 1, in which the first recruitment event for a given species was observed. March 1 was chosen as a starting date because it represents the seasonal cycle of recruitment in the New England marine system better than January 1 (J. F. Reinhardt pers. obs.). The length of the recruitment season was estimated as the number of days between the appearance of a species' first and last recruits on the settling panels. Additionally, the sum of all individuals for each species that recruited over a season was calculated to indicate whether temperature parameters influenced the overall recruit abundance. In addition to the time of first recruitment, we determined the average time required for the first $10 \%$ of recruits for each species to be recruited. Although the choice of this $10 \%$ value was somewhat arbitrary, it tended to remove extremes and better represent recruit populations.

We performed multivariate partial least squares regression (PLSR) using temperature parameters (i.e. monthly, seasonal and annually averaged tempera- 
tures and GDDs as well as cumulative summed GDD) as independent variables, and the date of first recruitment, length of the recruitment season or total recruits for all species as the multivariate dependent variables. Our initial set of predictors included 45 temperature variables, but we reduced the predictor set by eliminating variables that had negligible loadings. Our final predictor set included cumulative GDD from May to September and monthly GDD from May to September (this is because GDD did not accumulate until either April or May and no longer accumulated after September or October, making months outside this range less informative). Site was included as a factor using the addition of dummy variables and we included all GDD and site interaction terms in the model. PLSR was used to determine the predictability of recruitment and to determine independent variables that were most useful for prediction of recruitment variables (using loading weights). PLSR is a regression method that creates orthogonal transforms of both the dependent and independent variables to create latent variables. Latent variables are created to maximize the explained variance in the dependent variables. The creation of latent variables lowers the multidimensionality of the predictor set. In this case PLSR is useful because the orthogonal transform reduces the concern of multi-colinearity (and here our temperature parameters are not independent). To eliminate missing values in the data set we used the Day of Year 366 for the day of first recruitment for species that did not recruit during a given year. PLSR was implemented using 'pls' package (Mevik \& Wehrens 2007) in R 2.15 (R Development Core Team 2012).

Following PLSR we ran a series of univariate linear regressions on the time of first recruitment, duration of recruitment and the total number of recruits for all 18 species using cumulative GDD through September as the regressor (this variable was indicated as the most promising through the PLSR). To test the null hypothesis that the slope of the regression was equal to zero we ran a full factor regression with the regressor, site and interaction terms included in the model. If interaction terms were not significant the model was simplified to include only the GDD. If the simplified model was not selected, we added back site as a factor. This method of model selection favored parsimony and was utilized to avoid the inclusion of 'site' terms because site and GDD have the potential to be confounding (because sites have different GDD accumulation rates). By not including site terms we risked unexplained variance associated with site. Without the interaction terms this variance would manifest it- self in the intercept (a term we were less interested in for this test), not the slope of the equation.

The across-year average time of recruitment was also calculated. We then compared the time of year in which non-native species recruited to their year of invasion in southern New England for all species for which a sufficient recruitment record was available (species and dates first recorded in Long Island Sound or southern New England: Botryllus schlosseri, 1838; Halichondria bowerbanki, 1871; Styela clava, 1973; Botrylloides violaceus, 1974; Diplosoma listerianum, 1970s (we used 1975); Ascidiella aspersa, 1983; Bugula neritina, 1985; Membranipora membranacea, 1990; Didemnum vexillum, 2000, dates from J. T. Carlton unpubl. data). We performed this analysis by first ordering the species by the date on which each species first recruited for each year (2002 to 2008) and site and then averaging these rankings across all years. We then compared the inter-year averaged order of recruitment at each site to the order in which these species were first recorded in Long Island Sound (via a 2-tailed Spearman correlation). Other than PLSR, statistical analyses and null model analyses were performed using MATLAB 2009.

\section{RESULTS}

The temperature measurements showed distinct seasonal patterns between sites (Fig. 1). GLP was the warmest site in summer and the coldest in winter. The temperature variability at GLP is largely due to the shallow (approx. 1 to $1.5 \mathrm{~m}$ ) bathymetry of its inner harbor compared to the other sites. NK warmed slightly more slowly during spring and

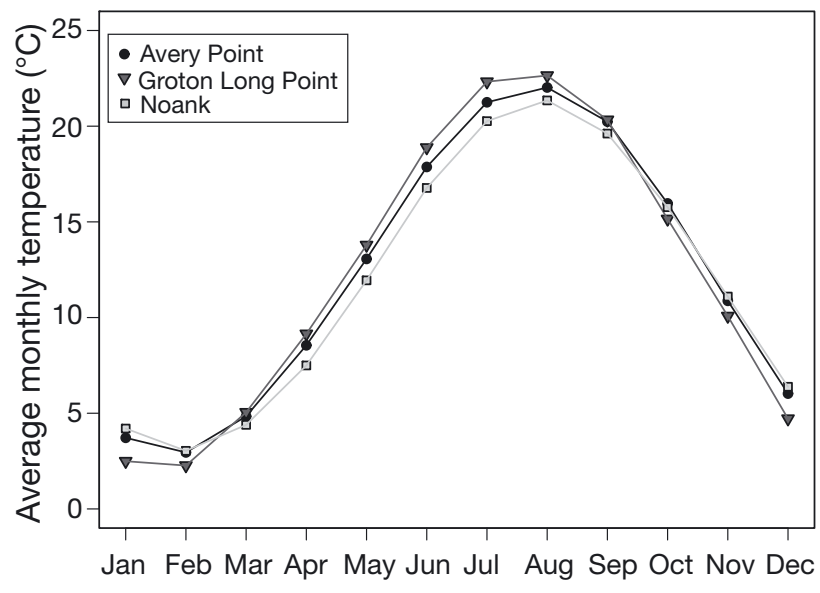

Fig. 1. Average monthly sea surface temperatures for 2002 to 2008 (interpolated values) 
summer but also cooled more slowly in fall and winter. AP presented intermediate rates of warming and cooling (Fig. 1). The maximum temperature for a single day during the entire study period was $25.6^{\circ} \mathrm{C}$ at GLP, $24.6^{\circ} \mathrm{C}$ at AP and $23.7^{\circ} \mathrm{C}$ at NK. Subtle but distinct seasonal thermal patterns among sites within $7 \mathrm{~km}$ of each other provide a source of temporal and spatial heterogeneity within the region.

\section{Niche Overlap}

The analysis of species recruitment overlap indicated that there was less temporal partitioning on a seasonal scale than would be expected at random at $\mathrm{NK}$ and AP, whereas the partitioning at GLP was no different than that predicted by the null model (Table 2). When all sites were included, the niche overlap pattern indicated that temperature was correlated negatively with overlap (Fig. 2).

\section{Phenology}

Species showed clear differences in their timing of recruitment based on GDDs and Day of Year. For the most part, representations of recruitment timing were consistent between Day of Year and GDD (Figs. 3 \& 4). Notable exceptions were for species that recruited later in the year (e.g. Bugula neritina) when GDD accumulate more rapidly (Fig. 3). The order of species recruitment among sites was quite consistent using Day of Year: species typically recruited at GLP then AP then NK, following the order of warming at these sites (Fig. 4). This pattern was less consistently represented using GDD. The order in which nonnative species recruited was positively correlated with the historical order in which these species invaded the region (Fig. 5). This pattern was consistent across all sites (AP: Spearman's $\rho=0.77, \mathrm{p}=$ 0.0214; GLP: Spearman's $\rho=0.72, p=0.037$; NK: Spearman's $\rho=0.87, \mathrm{p}=0.004$ ).
Table 2. Observed community overlap (OL) and median overlap, 95\% confidence intervals and p-values (p) for 10000 randomizations of the null model. The difference between the observed and median overlap of epifuanal communities from Avery Point, Groton Long Point and Noank is also shown. Negative values indicate less overlap than expected at random, and positive values indicate more overlap than expected at random

\begin{tabular}{|c|c|c|c|c|c|c|}
\hline & $\begin{array}{l}\text { Observed } \\
\text { OL }\end{array}$ & $\begin{array}{l}\text { Median } \\
\text { OL }\end{array}$ & $-95^{\circ}$ & $\mathrm{CI}-$ & $\mathrm{p}$ & Difference \\
\hline \multicolumn{7}{|c|}{ Avery Point } \\
\hline 2002 & 0.5121 & 0.4547 & 0.4365 & 0.5014 & 0.0115 & 0.0575 \\
\hline 2003 & 0.6018 & 0.5320 & 0.5134 & 0.5799 & 0.0048 & 0.0698 \\
\hline 2004 & 0.6197 & 0.5694 & 0.5524 & 0.6147 & 0.0170 & 0.0503 \\
\hline 2005 & \multicolumn{6}{|c|}{ NOT CALCULATED } \\
\hline 2006 & 0.4639 & 0.3736 & 0.3511 & 0.4302 & 0.0034 & 0.0903 \\
\hline 2007 & 0.5361 & 0.4214 & 0.4014 & 0.4743 & 0.0002 & 0.1147 \\
\hline 2008 & 0.4655 & 0.4186 & 0.3963 & 0.4801 & 0.0528 & 0.0469 \\
\hline \multicolumn{7}{|c|}{ Groton Long Point } \\
\hline 2002 & 0.3673 & 0.3607 & 0.3463 & 0.3879 & 0.2720 & 0.0066 \\
\hline 2003 & 0.6350 & 0.6150 & 0.5998 & 0.6502 & 0.0993 & 0.0200 \\
\hline 2004 & 0.5102 & 0.4870 & 0.4713 & 0.5220 & 0.0767 & 0.0231 \\
\hline 2005 & \multicolumn{6}{|c|}{ NOT CALCULATED } \\
\hline 2006 & 0.3971 & 0.4072 & 0.3890 & 0.4479 & 0.1867 & -0.0102 \\
\hline 2007 & 0.3455 & 0.3494 & 0.3273 & 0.4031 & 0.4071 & -0.0039 \\
\hline 2008 & 0.3785 & 0.3696 & 0.3486 & 0.4229 & 0.3187 & 0.0090 \\
\hline \multicolumn{7}{|c|}{ Noank } \\
\hline 2002 & 0.4213 & 0.3701 & 0.3530 & 0.4071 & 0.0060 & 0.0512 \\
\hline 2003 & 0.4277 & 0.2865 & 0.2623 & 0.3452 & 0.0002 & 0.1412 \\
\hline 2004 & 0.4930 & 0.3787 & 0.3595 & 0.4126 & 0.0000 & 0.1143 \\
\hline 2005 & 0.4492 & 0.3349 & 0.3121 & 0.3939 & 0.0009 & 0.1143 \\
\hline 2006 & 0.5122 & 0.4463 & 0.4283 & 0.4881 & 0.0034 & 0.0659 \\
\hline 2007 & 0.4709 & 0.3854 & 0.3656 & 0.4269 & 0.0002 & 0.0855 \\
\hline 2008 & 0.5336 & 0.4188 & 0.3989 & 0.4656 & 0.0002 & 0.1148 \\
\hline
\end{tabular}

\section{Multivariate partial least squares regression analysis}

The first 3 components of the multivariate PLSR explained $99.8 \%$ of the variation in the predictor variables (Table 3). Across all 3 multivariate PLSR (i.e. first recruitment date, length of recruitment and total individuals) similar predictor variables contributed most significantly to the components. Specifically, the interaction term of the GLP dummy variable and cumulative GDD through September made the most significant contribution to first component, the interaction term of the NK dummy variable and cumulative GDD through September made the most significant contribution to second component, while cumulative GDD through July and August were the most significant contributors to the third component. Time of first recruitment, duration of recruitment period and the total number of individuals showed a varying degree of predictability across species. Overall the PLSR for time of first recruitment and duration of recruitment showed that 8 species had significant coefficients of determination (with 3 components, 


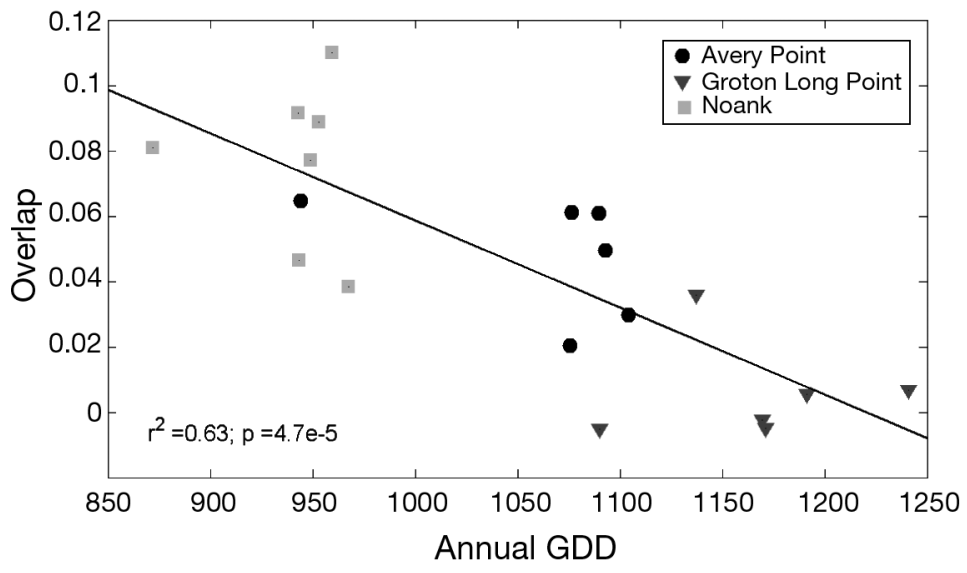

Fig. 2. Relationship between seasonal growing degree days (GDD) from 2002 to 2008 and community niche overlap, calculated as the difference between the observed overlap and the median of 10000 randomizations from the null model

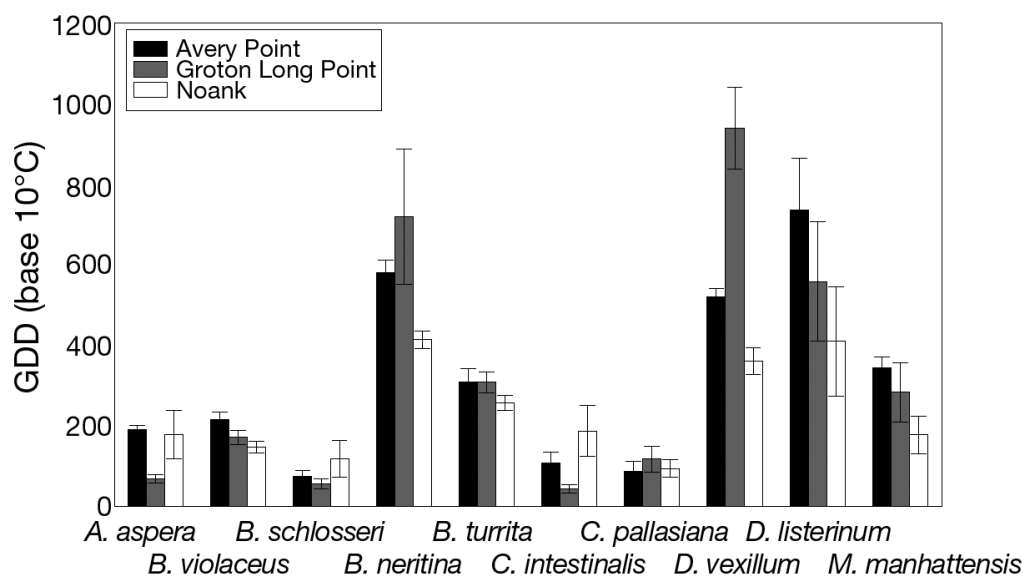

Fig. 3. Average (2002 to 2008) growing degree days (GDD; base $10^{\circ} \mathrm{C}$ ) required for the first $10 \%$ of individuals to be recruited for the 10 most abundant species. Error bars indicate $\pm 1 \mathrm{SE}$

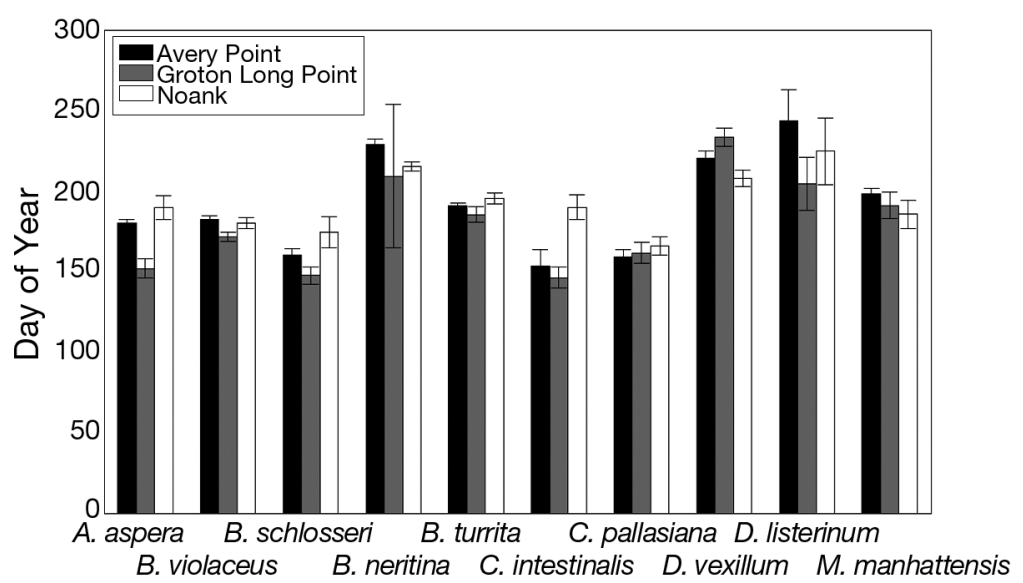

Fig. 4. Average (2002 to 2008) Day of Year on which the first individuals (post March 1) recruited for the 10 most abundant species. Error bars indicate $\pm 1 \mathrm{SE}$
Table 4), while there were 10 significant coefficients of determination for number of total recruitment. Predictions of the time of first recruitment and length of recruitment season of the non-native colonial tunicate Diplosoma listerianum showed marked improvement when the third component was added to the model suggesting that early summer predictors are more valuable for prediction of this species. Other species, such as the colonial ascidian Botryllus schlosseri only presented a significant prediction of sum of recruits. Only 2 species, the colonial bryozoans Schizoporella errata and Bugula neritina, never had any recruitment parameters that were significantly predicted. However, species without significant coefficients of determination in the multivariate PLSR may simply not contribute much information to the dependent latent variables.

\section{Univariate least squares regression analysis}

For all species with significant slope terms (i.e. Ascidiella aspersa, Botrylloides violaceus, Bugula turrita, Ciona intestinalis, Diplosoma listerianum and Molgula manhattensis), except for Didemnum vexillum, the first day of recruitment was negatively correlated with seasonal GDD (Botryllus schlosseri had site-specific interaction terms but slope was negative at 2 sites). When temperatures were warmer, recruitment was earlier.

Species that presented earlier onsets of recruitment typically exhibited longer recruitment seasons (Table 5), with the exception of Botrylloides violaceus which had a shorter recruitment season with higher temperatures. Furthermore, species with longer recruitment periods were also recruited in greater annual numbers overall. The species showing a positive correlation between GDD and the total number of individuals included Ascidiella aspersa, Botrylloides violaceus, Bugula turrita, Ciona intestinalis, and Diplosoma listerianum.

Although many (8 of 18) species displayed a shift in the onset of recruitment related to GDD, this did not necessarily alter the order in which species first recruited. Generally, species that recruited early in the year 
always recruited early, regardless of the temperature characteristics in that year. For instance, Obelia sp. and Cryptosula pallasiana were either first or second in the recruitment order 15 of 21 and 18 of 21 times, respectively (across all sites and years). Although differential shifts existed in the timing of recruitment, they did not necessarily change the order in which the species were recruited.

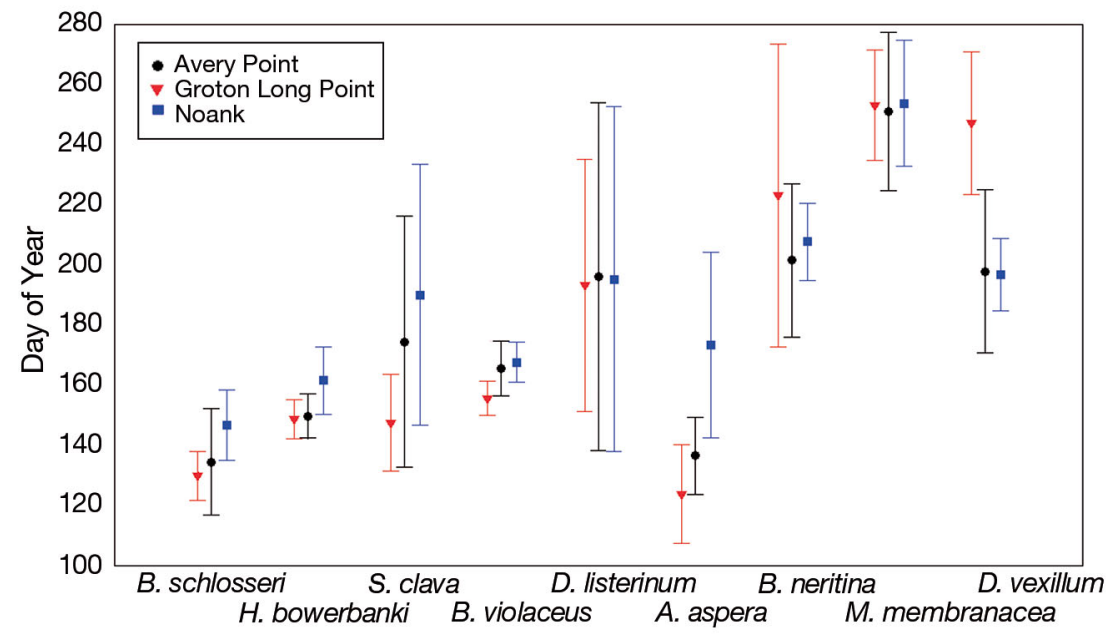

Fig. 5. Average Day of Year for the first recruitment of non-native species plotted in rank order of their first record in Long Island Sound in southern New England. Error bars indicate $\pm 1 \mathrm{SD}$

\section{DISCUSSION}

Our analysis showed that there was either a greater or equivalent amount of community niche overlap compared to what would be expected by chance at 3 sites in southern New England over $7 \mathrm{yr}$. It is possible that recruits within the epifaunal community present strong interspecific competitive interactions because of high overlap in their seasonal recruitment patterns. It is well recognized that members of hard-substrate epifaunal communities compete intensely for space (Jackson 1977, Nadakumar 1996). Despite a relatively high de-

Table 3. Predictor weights (of components 1 to 3) of the 3 partial least squares regression (PLSR) analyses describing the relationship between start of recruitment, duration of recruitment and sum of all recruits of epifaunal organisms (Table 1) from Avery Point (AP), Groton Long Point (GLP) and Noank (NK). Note: AP represents the base case of the dummy-variable regression and is not explicitly included as a parameter. Predictor weights represent the contribution of temperature variable to PLSR component; PLSR weights whose squares are larger than 0.2 are shown in bold. Cum: cumulative growing degree days

\begin{tabular}{|c|c|c|c|c|c|c|c|c|c|}
\hline \multirow[t]{2}{*}{ Component } & \multicolumn{3}{|c|}{ Start of recruitment } & \multicolumn{3}{|c|}{ Duration of recruitment } & \multicolumn{3}{|c|}{ Sum of recruits } \\
\hline & 1 & 2 & 3 & 1 & 2 & 3 & 1 & 2 & 3 \\
\hline CumMay & 0.00 & 0.00 & 0.15 & 0.00 & 0.00 & -0.13 & 0.00 & 0.00 & 0.15 \\
\hline CumJun & 0.00 & 0.00 & 0.40 & 0.00 & 0.00 & -0.41 & 0.00 & 0.00 & 0.39 \\
\hline CumJul & 0.00 & 0.00 & 0.48 & 0.00 & 0.00 & -0.51 & 0.00 & 0.00 & 0.49 \\
\hline CumAug & 0.00 & 0.00 & 0.44 & 0.00 & 0.00 & -0.45 & 0.00 & 0.00 & 0.50 \\
\hline CumSep & 0.00 & 0.00 & 0.40 & 0.00 & 0.00 & -0.37 & 0.00 & 0.00 & 0.44 \\
\hline May & 0.00 & 0.00 & 0.13 & 0.00 & 0.00 & -0.15 & 0.00 & 0.00 & 0.15 \\
\hline Jun & 0.00 & 0.00 & 0.25 & 0.00 & 0.00 & -0.28 & 0.00 & 0.00 & 0.24 \\
\hline Jul & 0.00 & 0.00 & 0.00 & 0.00 & 0.00 & 0.00 & 0.00 & 0.00 & 0.11 \\
\hline CumJun: GLP & 0.12 & 0.00 & 0.17 & -0.12 & 0.00 & -0.11 & 0.12 & 0.10 & 0.00 \\
\hline CumJul: GLP & 0.27 & 0.17 & 0.13 & -0.26 & -0.21 & 0.00 & 0.27 & 0.21 & 0.00 \\
\hline CumAug: GLP & 0.44 & 0.30 & 0.00 & -0.42 & -0.33 & 0.00 & 0.41 & 0.32 & 0.00 \\
\hline CumSep: GLP & 0.56 & 0.41 & 0.00 & -0.53 & -0.43 & 0.12 & 0.53 & 0.41 & 0.15 \\
\hline May: GLP & 0.00 & 0.00 & 0.00 & 0.00 & 0.00 & 0.00 & 0.00 & 0.00 & 0.00 \\
\hline Jun: GLP & 0.00 & 0.00 & 0.00 & 0.00 & 0.00 & 0.00 & 0.00 & 0.00 & 0.00 \\
\hline Jul: GLP & 0.15 & 0.11 & 0.00 & -0.15 & -0.11 & 0.00 & 0.15 & 0.11 & 0.00 \\
\hline Aug: GLP & 0.16 & 0.14 & 0.11 & -0.15 & -0.12 & 0.00 & 0.15 & 0.11 & 0.00 \\
\hline Sep: GLP & 0.12 & 0.11 & 0.00 & -0.12 & 0.00 & 0.11 & 0.12 & 0.00 & 0.00 \\
\hline CumJun: NK & 0.00 & 0.00 & 0.00 & 0.00 & 0.00 & 0.00 & 0.00 & 0.10 & 0.00 \\
\hline CumJul: NK & 0.18 & 0.24 & 0.11 & 0.19 & -0.23 & 0.00 & 0.19 & 0.25 & 0.00 \\
\hline CumAug: NK & 0.30 & 0.42 & 0.12 & 0.32 & -0.41 & 0.00 & 0.33 & 0.41 & 0.00 \\
\hline CumSep: NK & 0.39 & 0.56 & 0.13 & 0.43 & -0.55 & 0.00 & 0.43 & 0.54 & 0.00 \\
\hline Jul: NK & 0.11 & 0.15 & 0.00 & 0.12 & -0.15 & 0.00 & 0.12 & 0.15 & 0.00 \\
\hline Aug: NK & 0.12 & 0.19 & 0.00 & 0.13 & -0.18 & 0.00 & 0.13 & 0.16 & 0.00 \\
\hline Sep: NK & 0.00 & 0.14 & 0.00 & 0.10 & -0.14 & 0.00 & 0.10 & 0.13 & 0.00 \\
\hline
\end{tabular}


Table 4 . The percentage of variance explained (partial $\mathrm{r}^{2}$ ) for each dependent variable and independent variables calculated from loading weights of partial least squares regression (PLSR). $\mathrm{n}=21$, except Diplosoma listerianum $(\mathrm{n}=18)$ for start of recruitment. Bold indicates significance at $\alpha=0.05$

\begin{tabular}{|c|c|c|c|c|c|c|c|c|c|}
\hline \multirow[t]{2}{*}{ Component } & \multicolumn{3}{|c|}{ Start of recruitment } & \multicolumn{3}{|c|}{ Duration of recruitment } & \multicolumn{3}{|c|}{ Sum of recruits } \\
\hline & 1 & 2 & 3 & 1 & 2 & 3 & 1 & 2 & 3 \\
\hline Independent variables & 76.80 & 99.08 & 99.80 & 76.65 & 99.09 & 99.80 & 76.63 & 99.07 & 99.80 \\
\hline Ascidiella aspersa & 43.51 & 52.73 & 52.99 & 37.20 & 51.05 & 52.23 & 39.17 & 39.91 & 41.24 \\
\hline Botrylloides violaceus & 38.34 & 39.97 & 59.11 & 16.94 & 17.27 & 22.25 & 24.88 & 26.12 & 45.93 \\
\hline Botryllus schlosseri & 21.23 & 24.63 & 28.21 & 13.03 & 17.65 & 18.73 & 6.20 & 25.49 & 53.74 \\
\hline Bowerbankia gracilis & 0.32 & 3.10 & 3.90 & 10.72 & 12.71 & 12.72 & 44.55 & 48.37 & 50.18 \\
\hline Bugula neritina & 0.82 & 0.89 & 0.90 & 3.71 & 5.09 & 7.33 & 12.24 & 13.40 & 18.36 \\
\hline Bugula turrita & 40.13 & 42.74 & 58.11 & 48.39 & 50.88 & 66.09 & 42.52 & 42.58 & 52.56 \\
\hline Ciona intestinalis & 49.35 & 56.12 & 56.13 & 66.68 & 66.92 & 67.21 & 23.64 & 27.27 & 28.51 \\
\hline Cryptosula pallasiana & 0.82 & 2.04 & 24.03 & 4.21 & 4.21 & 37.54 & 1.14 & 2.12 & 11.09 \\
\hline Didemnum vexillum & 39.85 & 40.14 & 50.79 & 42.21 & 50.77 & 55.05 & 17.69 & 17.70 & 28.57 \\
\hline Diplosoma listerianum & 0.89 & 0.95 & 60.33 & 0.89 & 1.03 & 60.86 & 17.10 & 19.01 & 33.65 \\
\hline Electra crustulenta & 4.71 & 15.45 & 15.47 & 3.43 & 27.30 & 27.77 & 1.14 & 18.70 & 20.62 \\
\hline Electra pilosa & 8.63 & 8.73 & 18.23 & 0.34 & 4.20 & 5.23 & 10.47 & 42.50 & 45.18 \\
\hline Halichondria sp. & 7.68 & 7.90 & 8.06 & 3.47 & 7.32 & 7.74 & 1.27 & 41.14 & 47.30 \\
\hline Hydroides dianthus & 33.13 & 35.12 & 38.17 & 22.87 & 23.62 & 34.88 & 22.40 & 40.45 & 49.30 \\
\hline Molgula manhattensis & 43.79 & 43.87 & 66.82 & 57.12 & 59.77 & 69.33 & 6.67 & 27.19 & 59.55 \\
\hline Obelia sp. & 30.54 & 32.19 & 43.86 & 24.57 & 26.08 & 33.83 & 1.19 & 15.34 & 26.06 \\
\hline Schizoporella errata & 13.96 & 23.20 & 24.64 & 29.40 & 32.24 & 36.95 & 3.40 & 9.80 & 10.34 \\
\hline Spirorbis spp. & 6.12 & 6.33 & 7.76 & 6.44 & 6.70 & 6.71 & 34.97 & 42.81 & 42.81 \\
\hline
\end{tabular}

gree of overlap, we found that warmer sites tended to exhibit less community overlap than cooler sites. This pattern is what we expected given that shorter seasons require all local species to recruit in a smaller window of time.

Global climate change has been hypothesized to alter species interactions through a number of mechanisms, including shifting species ranges, driving species extinctions, altering ecosystem resilience and changing competition dynamics (Peñuelas \& Filella 2001, Walther et al. 2002, Menzel et al. 2006). Reviews often do not address how changes in competition may arise or how changes in competitive interactions may affect community assembly (but see Wolkovich \& Cleland 2011, Pau et al. 2011). Expanded resource spectra (in this case the time that recruitment occurs) offer one potential mechanism for altering interactions between species. Our results suggest that sites with higher temperatures have less community overlap than cooler sites. Thus, changes in the temperature regime may alter community characteristics and functions by altering important species interactions, such as competition and facilitation. Because within-site annual variation in temperature does not necessarily lead to changes in competition as measured by overlap, differences in community overlap may be caused by sustained temperature differences that operate on longer time scales.
The observed community niche overlap was never lower than would be expected at random, suggesting that the recruitment dynamics in the study system are likely constrained by environmental and physiological factors. Generally, communities constrained by abiotic factors will show greater recruitment symmetry between species (Albrecht \& Gotelli 2001). When competition is a dominant factor structuring communities, there will be inverse symmetry between species recruitment curves. Our betweensite comparisons suggest that GLP might be under more biological control (i.e. competition, facilitation and predation), whereas NK may be more constrained by physical factors, with AP exhibiting intermediate traits. This pattern fits well with our understanding of the temperature regimes at each site. GLP tended to warm up earliest in spring and remains warm for the longest period of time because of the shallow bathymetry of its harbor. NK remained coolest in summer, with AP representing the intermediate site. We therefore predict that the interspecific competition among recruits at NK will be greater than at the other sites because of the shared timing of recruitment, assuming an equal density of recruitment among sites. Differences in overlap between sites that are separated by $\sim 7 \mathrm{~km}$ suggest that phenologically driven community responses (and, thus, community heterogeneity) can occur at relatively small scales. 


\begin{tabular}{|c|c|c|c|c|c|c|c|c|}
\hline 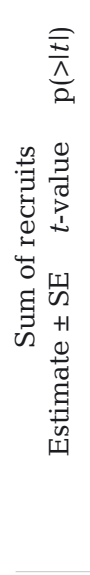 & 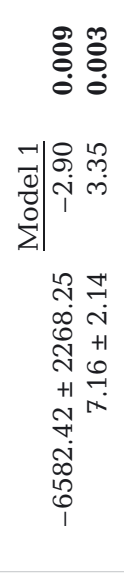 & 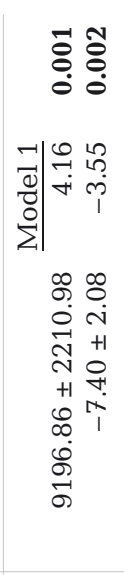 & 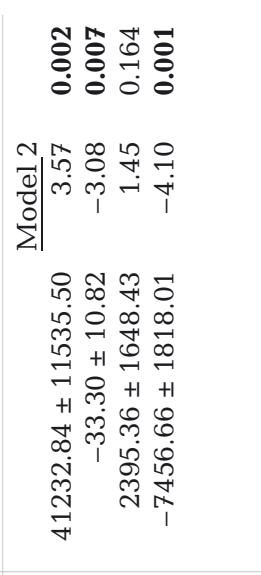 & 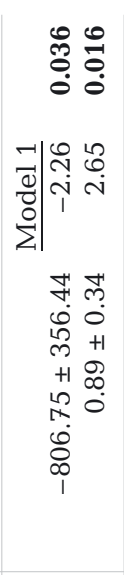 & & 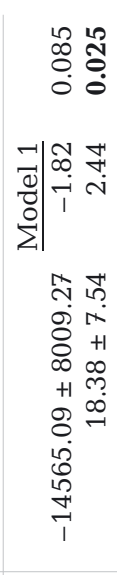 & 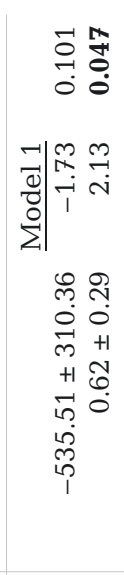 & 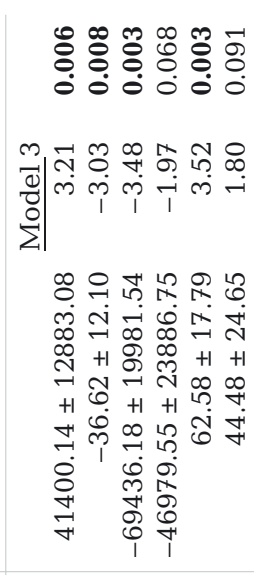 \\
\hline 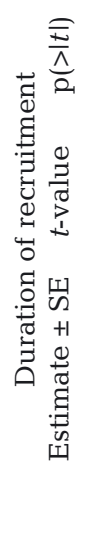 & 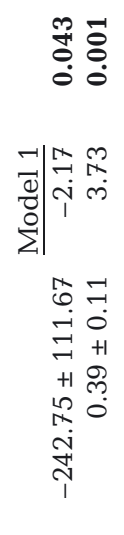 & 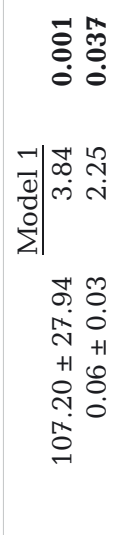 & 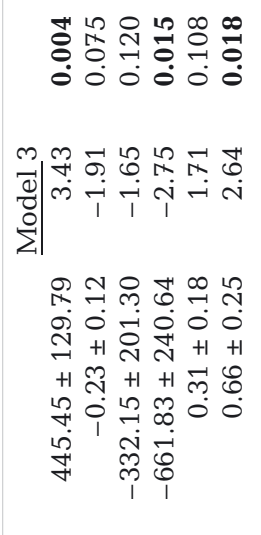 & & 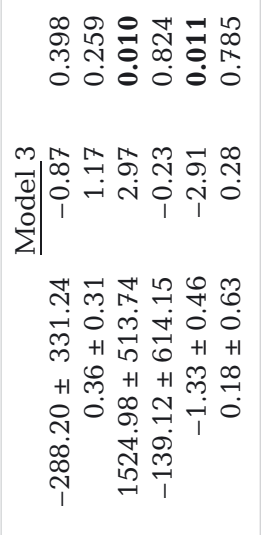 & 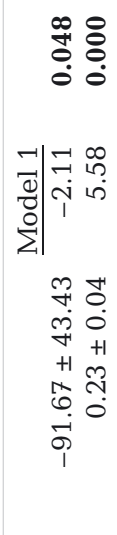 & 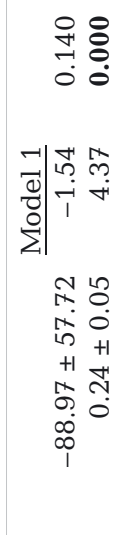 & 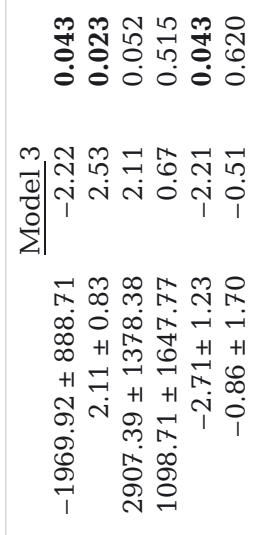 \\
\hline 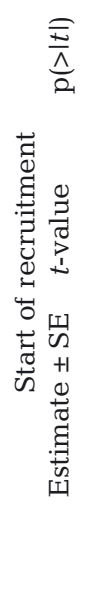 & 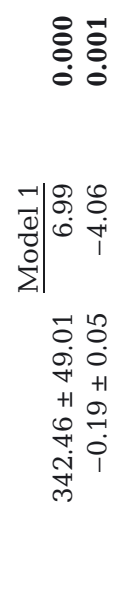 & 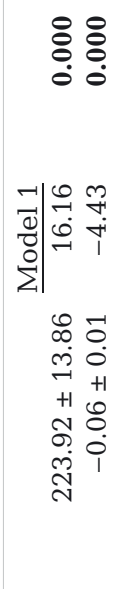 & 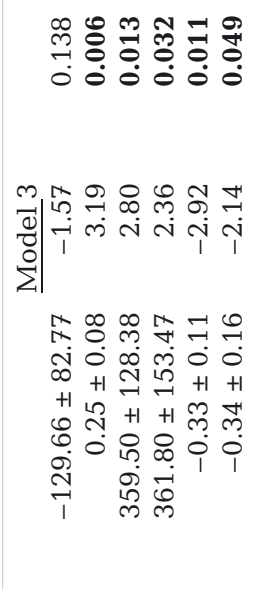 & & 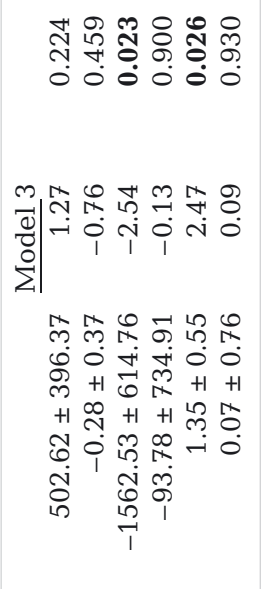 & 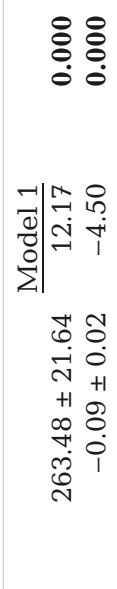 & 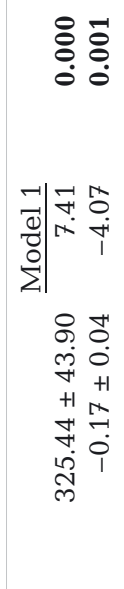 & $\left|\begin{array}{l}m \\
\vec{d} \\
\vec{\Sigma} \\
\dot{\Sigma}\end{array}\right|$ \\
\hline 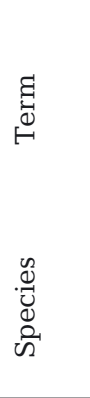 & 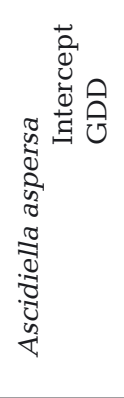 & 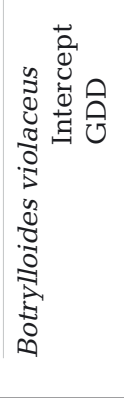 & 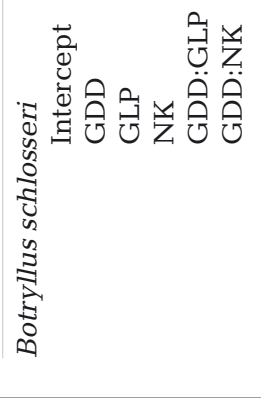 & 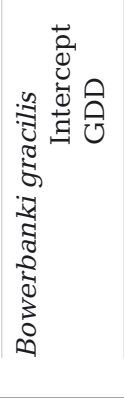 & 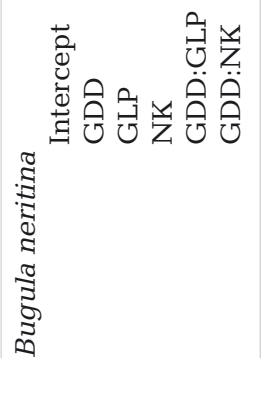 & 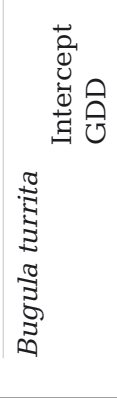 & 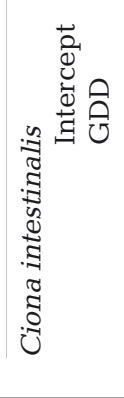 & 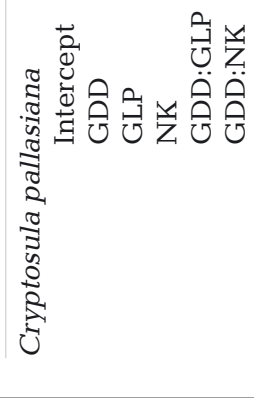 \\
\hline
\end{tabular}




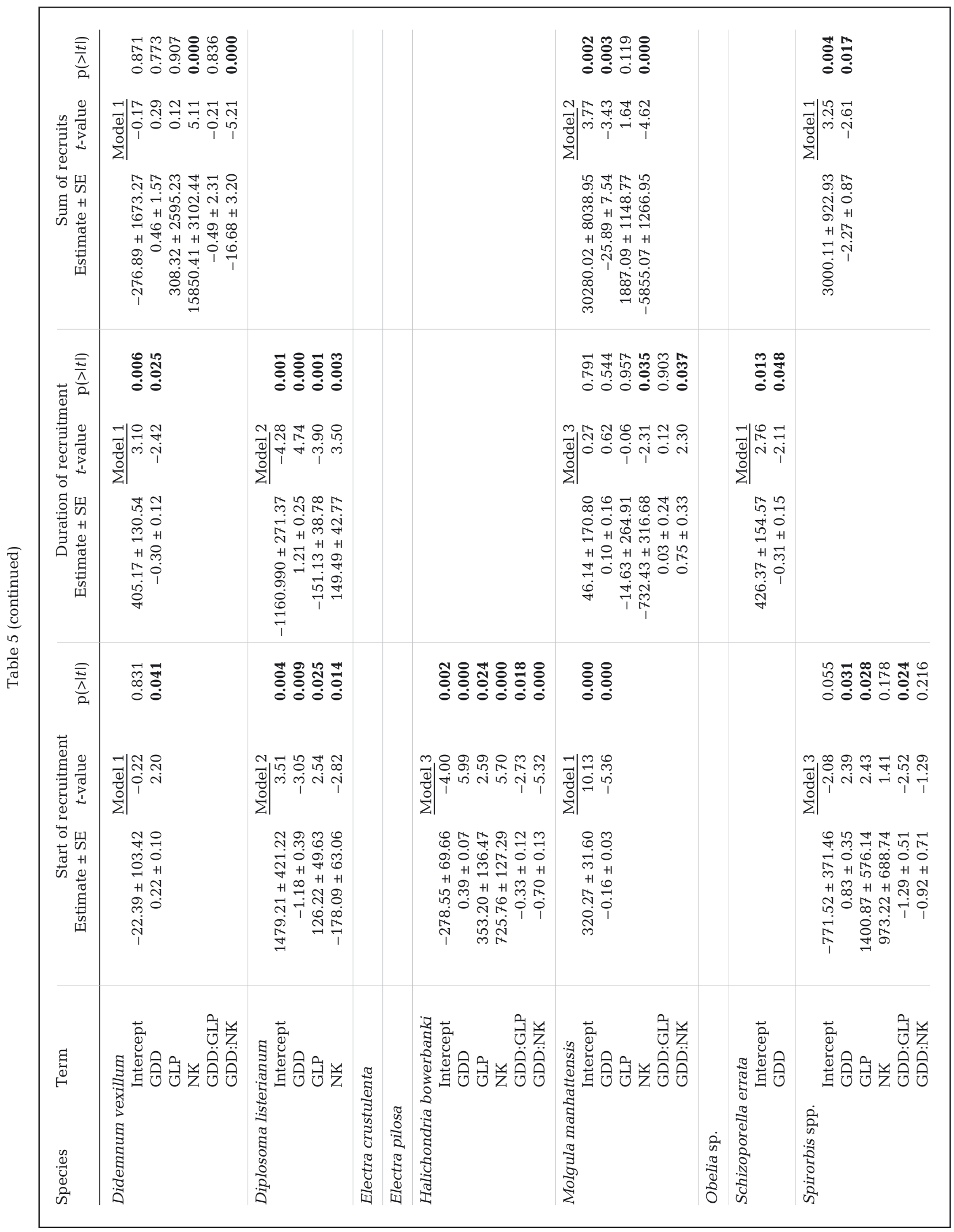


The phenology of many species is driven by temperature (Visser \& Both 2005). Here, we show that seasonal GDD can predict the first day of recruitment for many organisms in southern New England epifaunal communities. In some cases, this pattern was consistent for a species across sites, whereas in other cases, we observed idiosyncratic responses.

Although there is no a priori reason that the phenology of different species should be predicted by a single temperature parameter (although many temperature parameters covary), the relative loadings of components in PLSR and subsequent regression analysis indicated that site-specific factors are important in determining recruitment phenology. The variability in predictors further indicates the difficulty of developing phenological models that account for spatial and temporal heterogeneity at small scales. The predictor (cumulative GDD through September) that we identified as most useful through the PLSR was not a leading indicator of recruitment timing, and thus limits its utility in designing 'real time' prediction of recruitment. $\mathrm{Cu}$ mulative GDD through September provided more information than other predictors because it incorporates information from all previous months in a given season. Problems may arise when some environmental conditions are not accounted for, such as temperature variability and, possibly, day-length, salinity and productivity; however, this study has identified some general trends that may serve as a starting point for modeling and predicting future phenological patterns for the 18 investigated benthic invertebrate species.

Idiosyncratic responses to temperature variation are not unique to the present study. Forrest et al. (2010) report idiosyncratic changes in flowering time among subalpine plants in Colorado. Although the responses to temperature varied in magnitude among the examined benthic species, the interannual responses did not affect community overlap, and differential shifts in the timing of recruitment did not translate into clear differences in the order in which species were recruited.

We found that the length of the recruitment season was often predicted by GDD. The length of the recruitment season and first date of recruitment were not independent of each other, and in most cases, species that showed a shift in the beginning of recruitment in response to temperature also exhibited a longer recruitment season. When all species and sites were aggregated, there was a strong negative relationship detected between the length of the recruitment season and the date of first recruitment (i.e. species that recruit earlier also displayed longer recruitment seasons).
In contrast to previous findings (Stachowicz et al. 2002), we found that the onset of recruitment was positively correlated with temperature for both resident and non-native species. Here, we show that the timing of the first recruitment of many resident species can be predicted by temperature. For many resident species, the responses to shifts in temperature were similar to those of non-native species in that they recruited earlier under warmer temperatures (i.e. Bugula turrita, Ciona intestinalis and Molgula manhattensis). However, there are some species, both resident and non-native, that showed the opposite pattern. For example, the non-native tunicate Didemnum vexillum recruited later in the season when temperatures were higher. Complex responses to temperature variations make it difficult to generalize about species. Our results may be different from previous findings (i.e. Stachowicz et al. 2002) because we used recruitment data with a more complete temporal (i.e. year-round coverage) and spatial coverage and because our temperature data were collected at multiple sites.

Predicting the indirect effects of changes in overlap or competition can be difficult (Suttle et al. 2007). We interpreted overlap to reflect the relative potential for competition between recruits within the community. The decrease in community overlap coincident with decreased temperatures illustrates the type of changes that may be occurring along temperature gradients, such as related to latitude. A larger temporal domain effectively increases the access to resources, with the result that inter-specific competition among new recruits is reduced, assuming equal numbers of recruits.

Less overlap may be particularly important during the initial stages of an invasion but less important once an invasive species is fully established (Stachowicz \& Byrnes 2006). As resident species show a forward shift in their timing of recruitment unutilized resources become available to invading species. Interestingly, the average time of recruitment for invaders is correlated with the order in which they initially invaded the area. The most recent invaders for which we have recruitment data (e.g. Diplosoma listerianum, Bugula neritina and Didemnum vexillum) recruited later in the year. This pattern may occur because recent invaders are warmer water species (although this does not appear to be the case for one recent invader, D. vexillum; McCarthy et al. 2007). Additionally, because of shifts in the recruitment timing among resident organisms, there may be an 'open' recruitment window available for invaders toward the end of the year. Species such as 
D. vexillum are known to be weak competitors and can be overwhelmed in habitats with high recruitment (Janiak et al. 2013). By recruiting at the end of the season, $D$. vexillum may avoid periods where recruitment (and competition with other recruits) is highest. We have yet to obtain recruitment data for the most recent tunicate invader (Clavelina lepadiformis) along the Connecticut coast (Reinhardt et al. 2010), but data from this species would enable an additional test of this hypothesis. Regardless of whether this hypothesis is correct, there appears to be different controls on the timing of recruitment for invasive species (see also Reinhardt et al. 2012). From the few years of data that have been collected, we observed that the latest recruiting species have shifted their time of first recruitment earlier in the season. The exact reason for this pattern is not entirely known. For B. neritina and D. listerianum, the effect may be temperature-related or could be a sampling effect caused by a larger population size. This pattern may also be the result of a series of populations evolving toward earlier recruitment.

Acknowledgements. This research was partially supported by U.S. EPA STAR and NSF grants awarded to R.B.W. and R.W.O. J.F.R. was supported by a fellowship from the Long Island Sound Study for a portion of this work. Thanks to J. Carlton, R. Colwell, D. Avery and M. Whitney for helpful information and suggestions. Many thanks to the individuals who helped collect recruitment data and the anonymous reviewer.

\section{LITERATURE CITED}

Abrams PA (1980) Consumer functional response and competition in consumer-resource systems. Theor Popul Biol 17:80-102

Albrecht M, Gotelli NJ (2001) Spatial and temporal niche partitioning in grassland ants. Oecologia 126:134-141

> Altman S, Whitlatch RB (2007) Effects of small-scale disturbance on invasion success in marine communities. J Exp Mar Biol Ecol 342:15-29

- Cross HZ, Zuber MS (1972) Prediction of flowering dates in maize based on different methods of estimating thermal units. Agron J 64:351-355

Dijkstra JA, Westerman EL, Harris LG (2011) The effects of climate change on species composition, succession and phenology: a case study. Glob Change Biol 17:2360-2369

Edwards KF, Stachowicz JJ (2012) Temporally varying larval settlement, competition, and coexistence in a sessile invertebrate community. Mar Ecol Prog Ser 462:93-102

Forrest J, Inouye DW, Thomson JD (2010) Flowering phenology in subalpine meadows: Does climate variation influence community co-flowering patterns? Ecology 91: 431-440

Gotelli NJ, Graves GR (1996) Null models in ecology. Smithsonian Institution Press, Washington, DC
Inger RF, Colwell RK (1977) Organization of contiguous communities of amphibians and reptiles in Thailand. Ecol Monogr 47:229-253

Jackson JB (1977) Competition on marine hard substrata: the adaptive significance of solitary and colonial strategies. Am Nat 111:743-767

Janiak DS, Osman RW, Whitlatch RB (2013) The role of species richness and spatial resources in the invasion success of the colonial ascidian Didemnum vexillum Kott, 2002 in eastern Long Island Sound. J Exp Mar Biol Ecol 443:12-20

Karlson RH, Osman RW (2012) Species composition and geographic distribution of invertebrates in fouling communities along the east coast of the USA: a regional perspective. Mar Ecol Prog Ser 458:255-268

Legendre P, Legendre L (1998) Numerical ecology, 2nd English edn. Elsevier, Amsterdam

Loreau M (1989) Coexistence of temporally segregated competitors in a cyclic environment. Theor Popul Biol 36: 181-201

Loreau M (1992) Time scale of resource dynamics and coexistence through time partitioning. Theor Popul Biol 41: 401-412

McCarthy A, Osman RW, Whitlatch RB (2007) Effects of temperature on growth rates of colonial ascidians: a comparison of Didemnum sp. to Botryllus schlosseri and Botrylloides violaceus. J Exp Mar Biol Ecol 342:172-174

> Menzel A, Sparks TH, Estrella N, Koch E and others (2006) European phenological response to climate change matches the warming pattern. Glob Change Biol 12: 1969-1976

Mevik BH, Wehrens R (2007) The pls package: principal component and partial least squares regression in $\mathrm{R}$. J Stat Soft 18:1:24

$>$ Mook DH (1981) Effects of disturbance and initial settlement on fouling community structure. Ecology 62: $522-526$

> Nandakumar K (1996) Importance of timing of panel exposure on the competitive outcome and succession of sessile organisms. Mar Ecol Prog Ser 131:191-203

> Osman RW (1977) The establishment and development of a marine epifaunal community. Ecol Monogr 47:37-63

> Osman RW, Whitlatch RB, Malatesta RJ (1992) Potential role of micro-predators in determining recruitment into a marine community. Mar Ecol Prog Ser 83:35-43

Pau S, Wolkovich EM, Cook BI, Davies TJ, Kraft NJB, Bolmgre KE, Betancourt JL, Cleland EE (2011) Predicting phenology by integrating ecology, evolution and climate science. Glob Change Biol 17:3633-3643

> Peñuelas J, Filella I (2001) Phenology: responses to a warming world. Science 294:793-795

R Development Core Team (2012) R: a language and environment for statistical computing. R foundation for statistical computing, Vienna. www.r-project.org

Reinhardt JF, Stefaniak LM, Hudson DM, Mangiafico J, Gladych R, Whitlatch RB (2010) First record of the nonnative light bulb tunicate Clavelina lepadiformis (Müller, 1776) in the northwest Atlantic. Aquat Invasions 5: 185-190

Reinhardt JF, Osman RW, Whitlatch RB (2012) A phenological mid-domain analysis of non-native and native species recruitment richness. J Ecosyst Ecogr 2:4

> Schoener TW (1974) The compression hypothesis and temporal resource partitioning. Proc Natl Acad Sci USA 71: 4169-4172 
Sousa WP (1979) Disturbance in marine intertidal boulder fields: the nonequilibrium maintenance of species diversity. Ecology 60:1225-1239

Stachowicz JJ, Byrnes J (2006) Species diversity, invasion success, and ecosystem functioning: disentangling the influence of resource competition, facilitation and extrinsic factors. Mar Ecol Prog Ser 311:251-262

Stachowicz JJ, Terwin JR, Whitlatch RB, Osman RW (2002) Linking climate change and biological invasions: ocean warming facilitates nonindigenous species invasions. Proc Natl Acad Sci USA 99:15497-15500

Suttle KB, Thompson MA, Power ME (2007) Species interaction reverse grassland responses to changing climate. Science 315:640-642

Tarjuelo I, Posada D, Crandall KA, Pascual M, Turon X (2001) Cryptic species of Clavelina (Ascidiacea) in two different habitats: harbours and rocky littoral zones in the northwestern Mediterranean. Mar Biol 139:455-462

Tokeshi M (1986) Resource utilization, overlap and tempo-

Editorial responsibility: Romuald Lipcius,

Gloucester Point, Virginia, USA ral community dynamics: a null model analysis of an epiphytic chironomid community. J Anim Ecol 55: 491-506

Visser ME, Both C (2005) Shifts in phenology due to global climate change: the need for a yardstick. Proc Biol Sci 272:2561-2569

> Walther GR, Post E, Convey P, Menzel A and others (2002) Ecological responses to recent climate change. Nature 416:389-395

> Westerman EL, Whitlatch RB, Dijkstra JA, Harris LG (2009) Variation in brooding period masks similarities in response to changing temperatures. Mar Ecol Prog Ser 391:13-19

- Wolkovich EM, Cleland EE (2011) The phenology of plant invasions: a community ecology perspective. Front Ecol Environ 9:287-294

> Yang LH, Rudolf VHW (2010) Phenology, ontogeny and the effects of climate change on the timing of species interactions. Ecol Lett 13:1-10

Submitted: October 5, 2012; Accepted: May 29, 2013 Proofs received from author(s): August 9, 2013 